2017-04

Do intracoelomic telemetry transmitters alter the post-release behaviour of migratory fish?

\author{
Wilson, Alexander
}

http://hdl.handle.net/10026.1/11422

10.1111/eff.12275

Ecology of Freshwater Fish

Wiley

All content in PEARL is protected by copyright law. Author manuscripts are made available in accordance with publisher policies. Please cite only the published version using the details provided on the item record or document. In the absence of an open licence (e.g. Creative Commons), permissions for further reuse of content should be sought from the publisher or author. 


\title{
Do intracoelomic telemetry transmitters alter the post-release behaviour of migratory fish?
}

\author{
Alexander D.M. Wilson ${ }^{1,2}$, Todd A. Hayden ${ }^{2,3}$, Christopher S. Vandergoot ${ }^{4}$, Richard T. Kraus ${ }^{5}$, John M. Dettmers ${ }^{6}$, \\ Steven J. Cooke ${ }^{2}$, Charles C. Krueger ${ }^{7}$ \\ ${ }^{1}$ School of Life and Environmental Sciences, Centre for Integrative Ecology, Deakin University, 75 Pigdons Road, Waurn Ponds, Geelong, Vic., Australia \\ ${ }^{2}$ Fish Ecology and Conservation Physiology Laboratory, Department of Biology, Carleton University, 1125 Colonel By Drive, Ottawa, ON K1S 5B6, Canada \\ ${ }^{3}$ Department of Fisheries and Wildlife, Michigan State University, Hammond Bay Biological Station, 11188 Ray Road, Millersburg, MI 49759, USA \\ ${ }^{4}$ Division of Wildlife, Sandusky Fisheries Research Station, Ohio Department of Natural Resources, 305 E. Shoreline Drive, Sandusky, OH 44870, USA \\ ${ }^{5}$ U.S. Geological Survey - Great Lakes Science Center, 6100 Columbus Avenue, Sandusky, OH 44870, USA \\ ${ }^{6}$ Great Lakes Fishery Commission, 2100 Commonwealth Blvd. Ste. 100, Ann Arbor, MI USA \\ ${ }^{7}$ Center for Systems Integration and Sustainability, Michigan State University, 1405 South Harrison Road, 115 Manly Miles Building, East Lansing, \\ MI 48823-5243, USA
}

Accepted for publication December 4, 2015

Abstract - Electronic tags have become a common tool in fish research, enhancing our understanding of how fish interact with their environment and move among different habitats, for estimating mortality and recording internal physiological states. An often-untested assumption of electronic tagging studies is that tagged fish are representative of untagged conspecifics and thus show 'normal' behaviour (e.g. movement rates, swimming activity, feeding).

Here, we use a unique data set for potamadromous walleye (Sander vitreus) in Lake Huron and Lake Erie tributaries to assess whether the lack of appropriate controls in electronic tagging could seriously affect behavioural data. We used fish tagged in previous years and compared their migratory behaviour during the spawning season to fish tagged in a current year at the same location. The objective of the study was to determine whether intracoelomic acoustic tag implantation altered downstream movement of walleye after spawning. Fish tagged in a given season travelled slower downstream from two river spawning sites than fish tagged in previous years. Fish tagged one or two years earlier showed no differences between each other in downstream travel time, in contrast to fish tagged in a given year. Our results support notions that standard collection and intracoelomic tagging procedures can alter short-term behaviour (i.e. days, weeks, months), and as such, researchers should use caution when interpreting data collected over such time periods. Further, whenever possible, researchers should also explicitly evaluate post-tagging effects on behaviour as part of their experimental objectives.

Key words: fish tagging; transmitter implantation; tagging effects; behaviour; surgery

\section{Introduction}

Over the past several decades, electronic tags (both those that transmit - biotelemetry - and those that log data - biologgers) have become common tools in fish research (Lucas \& Baras 2000; Cooke et al. 2013). Electronic tagging studies have greatly enhanced our understanding of how fish interact with their environment (i.e. habitat use and preference, environmental relations), and the extent and timing of movement among different habitat units (reviewed in
Lucas \& Baras 2000). Electronic tags also provide opportunities to quantify fish mortality (both natural and fishery related; Hightower et al. 2001) and if equipped with sensors, to characterise the internal or external environment of tagged individuals (e.g. depth, temperature, heart rate, activity levels; Cooke et al. 2004). The range of fish species studied using electronic tags, and the locales of such studies, has expanded greatly beyond early work on sport fish in North America and Europe. Example studies include resident fish in small Arctic lakes (Dick et al. 2009),

Correspondence: Alexander D.M. Wilson, School of Life and Environmental Sciences, Centre for Integrative Ecology, Deakin University 75 Pigdons Road, Waurn Ponds, Geelong, Vic., Australia. E-mail: alexander.wilson@ymail.com 
riverine fish in South America (Hahn et al. 2011) and Africa (Thorstad et al. 2001), reservoir fish in Thailand (Mitamura et al. 2008), as well as stream fish in Australia (Khan et al. 2004). Collectively, data emanating from electronic tagging studies have revolutionised our understanding of the ecology and natural history of fish while also yielding critical information to conserve and manage fish populations and their habitats (Cooke et al. 2013).

As with all techniques that involve marking or tagging fish, the use of electronic tags presents a number of potential biases or issues that must be considered (Nielsen 1992; McKenzie et al. 2012). For electronic tags, perhaps one of the most pervasive issues relates to the effects of the tagging procedure and the presence of the tag on or in the fish (Bridger \& Booth 2003). Although a wide range of potential electronic tag types and sizes can be applied to freshwater fish (reviewed in Cooke et al. 2012), a common feature is the need to capture the animal, restrain it for tagging (which may involve anaesthesia), tag the fish (which can be done externally, gastrically or via intracoelomic implantation) and then to release the fish. An often-untested assumption of electronic tagging studies is that tagged fish are representative of untagged conspecifics and thus show 'normal' behaviour (Olney et al. 2006; Brown et al. 2011; Liedtke \& Rub 2012). Given that data on fish behaviour and spatial ecology are of critical importance for defining ecological relationships and informing conservation and management, ill-informed management decisions may result if tags or tagging procedures alter the behaviour of tagged individuals (Brown et al. 2011).

The most common approach for tagging freshwater fish with electronic tags is intracoelomic implantation as this method corresponds to an increased probability of tags being retained throughout an animal's life (Jepsen et al. 2002). Although considered more invasive than some other methods (e.g. external tagging) due to the need for laparotomy and sedation (Jepsen et al. 2002; Cooke et al. 2012; Thorstad et al. 2013), a growing body of research has helped refine tagging practices to maximise postsurgery survival and minimise behavioural effects. A review of telemetry studies that have explicitly examined the effects of intracoelomic implantation on fish (Cooke et al. 2011) revealed that the typical project design involved comparing control fish (untagged), sham controls (anaesthetised but not tagged or anaesthetised and laparotomy performed but not tagged) and various tag treatments (e.g. different sizes or tags) with respect to some endpoint. Cooke et al. (2011) noted that most tagging effects studies occurred in laboratory environments using variables such as growth, survival, wound healing and swimming performance (in a swim tunnel) as indicators of effects. In contrast, behaviour of wild fish postrelease was rarely used (e.g. Hondorp et al. 2015). This is extraordinary considering the critical importance of the assumption that tagged fish and untagged conspecifics exhibit similar behavioural attributes. This discrepancy is attributable to the difficulty in characterising 'normal' behaviour of control fish without the application of an electronic tag, especially those that undertake large-scale movements and migrations. Pure control groups for comparison are not logistically feasible. To address this difficulty, several studies (Hockersmith et al. 2003; Matter \& Sandford 2003) have compared different tag types (e.g. PIT vs. radio), tag sizes or tagging methods (e.g. external vs. gastric vs. intracoelomic) in the field using sensory tags but they all suffer from the same lack of true controls (but see Jepsen \& Aarestrup 1999). Of particular concern are the short-term (i.e. days, weeks, months) behavioural consequences of tagging and evaluating whether some data should be disregarded (i.e. censored) until fish have resumed 'normal' behaviour. Indeed, many studies dismiss data from the first day or week post-tagging assuming that behaviour was altered although being unable to test for this effect.

Here, we take advantage of a unique data set to address the deficiency of appropriate controls in electronic tagging behavioural assessments. Our objective was to determine whether intracoelomic acoustic tag implantation caused short-term $(<1$ year) effects on downstream movement of postspawning walleye in Lakes Huron and Erie. Walleye are iteroparous and undertake annual spawning migrations from the Great Lakes to tributary habitats for spawning and then return to the lakes after spawning. Although the degree of spawning site fidelity of populations in the Great Lakes is not well understood, some walleye populations are known to return to the same spawning site over multiple years (Crowe 1962). We addressed our objective by comparing the elapsed time of downstream movement of postspawning walleye to those tagged the previous year at the same locale. Similarly, long-term effects were assessed by comparing the duration of downstream movements of walleye tagged 2 years earlier to those tagged 3 years earlier at the same location. Downstream travel time was quantified by calculating the difference between time of detection for each tagged walleye on acoustic telemetry receiver lines located near known walleye spawning regions and those at the river mouths of the Tittabawassee (Lake Huron) and Maumee (Lake Erie) rivers. Although admittedly an imperfect control, we assume that short-term behavioural effects of tagging have been ameliorated in fish tagged 10+ months earlier. This study represents one of the few behavioural assessments of wild fish in this context (but 
see Peat et al. 2015) and explores the short-term consequences of electronic tag implantation. Such information is essential for evaluating whether data require censoring after release to ensure that inferences regarding behaviour of individual fish are representative of untagged conspecifics.

\section{Methods}

The Tittabawassee River watershed drains approximately $6400 \mathrm{~km}^{2}$ of agricultural land in the central portion of Michigan's Lower Peninsula and contains important walleye spawning habitat. The Tittabawassee River is a tributary to the Saginaw River and enters the river approximately $35 \mathrm{~km}$ upstream from Saginaw Bay, Lake Huron. Multiple man-made dams restrict upstream movement of walleye throughout the Tittabawassee River watershed and limit spawning to a $35 \mathrm{~km}$ reach from Dow Dam in Midland, MI, downstream to the confluence of the Saginaw and Tittabawassee rivers.

The Maumee River watershed is the largest drainage in the Great Lakes and encompasses more than $21,000 \mathrm{~km}^{2}$ of mostly agricultural land in north-western Ohio and south-eastern Michigan. The lower $25 \mathrm{~km}$ of river is strongly influenced by Lake Erie and is considered a freshwater estuary. Primary spawning ground for walleye in the Maumee River starts approximately $25 \mathrm{~km}$ upstream from Lake Erie and extends upstream to the first dam located approximately $50 \mathrm{~km}$ from the river mouth.

Adult walleye in spawning condition were collected from the Tittabawassee and Maumee rivers in 2011 and 2012 (Tables 1 and 2). Walleye were collected on 4-5 April 2011 and 20 March 2012, near Dow Dam in the Tittabawassee River by Michigan Department of Natural Resources personnel operating boat-mounted electroshocking equipment. Walleye collection in the Maumee River occurred on 29-31 March 2011, 7 April 2011 and 27 March 2012 at Orleans Park (Perrysburg, OH) using boat-mounted electroshocking equipment operated by the Ohio Department of Natural Resources. Orleans Park is approximately $25 \mathrm{~km}$ upstream of Lake Erie. After capture, fish selected for tagging were transported to streamside tanks located near their capture location for processing (total holding time prior to tagging $\sim 1 \mathrm{~h}$ ). Biological characteristics (total length, sex) and dorsal fin clips were collected and paired anchor tags (Floy Tag Inc, Seattle, WA, USA) were inserted between the pterygiophores below the base of the second dorsal fin to allow individuals to be identified during later implantation of acoustic tags.

Walleye were anaesthetised using a portable electroanaesthesia unit (Smith-Root, pulsed DC, $35 \mathrm{~V}$,
Table 1. Number of walleye tagged with acoustic transmitters detected moving downstream in the Tittabawassee and Saginaw rivers during spring 2011, 2012 and 2013 spawning seasons. Sex ( $M=$ male, $F=$ female) was determined for all fish at tagging, release is the year fish were released (2011 or 2012), $N$ is the number of fish tagged, and values for 'spawn event' are the number of walleye detected moving downstream in 2011, 2012 and 2013 between receiver lines located at the mouth of the Tittabawassee and Saginaw rivers (Lake Huron).

\begin{tabular}{llllll}
\hline & \multicolumn{5}{l}{ Spawn event } \\
\cline { 4 - 6 } Sex & Release & $N$ & 2011 & 2012 & 2013 \\
\hline F & 2011 & 101 & 98 & 60 & 37 \\
M & 2011 & 98 & 92 & 42 & 27 \\
F & 2012 & 30 & & 28 & 16 \\
M & 2012 & 29 & & 29 & 19 \\
\hline
\end{tabular}

Table 2. Number of tagged walleye in the Maumee River detected moving downstream during the 2012 and 2013 spawning seasons. Sex ( $M=$ male, $\mathrm{F}=$ female) was determined for all fish at tagging, release is year fish were tagged and released (2011 or 2012), $N$ is the number of fish tagged, and values for 'spawn event' are the number of walleye detected on acoustic receiver lines moving downstream in 2012 and 2013 in the Maumee River (Lake Erie).

\begin{tabular}{llrrr}
\hline & & \multicolumn{3}{c}{ Spawn event } \\
\cline { 3 - 5 } Sex & Release & $N$ & 2012 & 2013 \\
\hline F & 2011 & 97 & 36 & 28 \\
M & 2011 & 103 & 3 & 4 \\
F & 2012 & 32 & 30 & 5 \\
M & 2012 & 1 & 1 & 1 \\
\hline
\end{tabular}

$3 \mathrm{~s}$ treatment period) (Vandergoot et al. 2011). Anaesthetised fish were placed in a cushioned foam cradle and river water with a pump continuously irrigated the gills during surgery. All surgical tools and acoustic tags were sterilised prior to surgery, and the tag was inserted into the coelomic cavity through a small incision located on the centreline of the ventral surface of the fish. After the tag was inserted, incisions were closed using 2-3 interrupted sutures (Ethicon PDS-II size 2-0, monofilament). After surgery, walleye were transferred to stream-side recovery tanks containing fresh circulating river water. Once individual fish regained equilibrium, they were released into the river near the capture location. On average, each surgery took $2.5 \mathrm{~min}$ and fish were released $30 \mathrm{~min}$ after the procedure. I-Button temperature loggers (model DS1921Z, $6 \mathrm{~mm} \times 16 \mathrm{~mm}$; Maxim Integrated Products, San Jose, CA, USA) were attached to acoustic tags (Vemco V16-4H tags, estimated life 1338 days, average nominal delay $90 \mathrm{~s}, 152 \mathrm{~dB}$ output, $24 \mathrm{~g}$ in air, $68 \mathrm{~mm} \times 16 \mathrm{~mm}$ dia) with hot glue and waterproofed using Plasti Dip (Performix Brand, Blaine, MN, USA) multipurpose rubber coating prior to implantation (mass $\sim 29 \mathrm{~g}$ ). 
Omnidirectional acoustic receivers (VR2W, 69 kHz, Vemco Ltd, Halifax, NS, Canada), deployed as part of the Great Lakes Acoustic Telemetry Observing System Network (http://data.glos.us/glatos), were used to detect walleye movements to and from spawning habitat in both lakes. In Lake Huron, two acoustic receiver lines were positioned near the mouths of the Saginaw and Tittabawassee rivers (Fig. 1). Receiver lines in the Tittabawassee River were first deployed in spring 2011 and removed in autumn 2011 to prevent the loss or damage of equipment from ice scour during winter. Beginning in spring 2012, the Tittabawassee River receiver line was maintained continuously through autumn 2013 (Fig. 1). Initial deployment of the Saginaw River receiver line occurred in spring 2011 and was continuously maintained through autumn 2013. The upstream acoustic receiver line in the Maumee River (Fig. 1, MAU-1) was located approximately $2.5 \mathrm{~km}$ downstream of the release location and consisted of two seasonal receivers (retrieved in autumn and deployed in spring) and one receiver deployed continuously from spring 2011 through summer 2012. In 2013 , receivers were deployed seasonally at the same locations as previous years. An additional receiver line located approximately $12 \mathrm{~km}$ downstream of the release location was deployed seasonally in 2012 and
2013 (Fig. 1, MAU-2). Spring receiver deployments occurred prior to walleye spawning, and retrieval of receivers in autumn occurred several months after the spring spawning season.

In the Maumee River, receivers were located, downstream of known spawning grounds, at a single location in 2011 and two locations in 2012 and 2013 (Fig. 1). Each receiver line consisted of at least two acoustic receivers. All receiver lines were initially deployed in March 2011 and retrieved, downloaded and redeployed in summer 2012 and 2013.

Detections on the Tittabawassee, Maumee and Saginaw rivers receiver lines represent either upstream or downstream movements. Direction and duration of walleye movements were determined by the order in which walleye were detected on receiver lines. Downstream travel (egress) time of walleye tagged in the Tittabawassee River was calculated as the difference (in hours) between the last detection on the Tittabawassee River receiver line and the first detection event at the Saginaw River receiver line. Duration of egress in the Maumee River was defined as the time difference between the last detection on the upstream receiver line (Fig. 1, MAU-1) and the first detection on the downstream receiver line (Fig. 1, MAU-2) for each fish. To assess the effects of the tagging procedure on walleye behaviour, only the first downstream
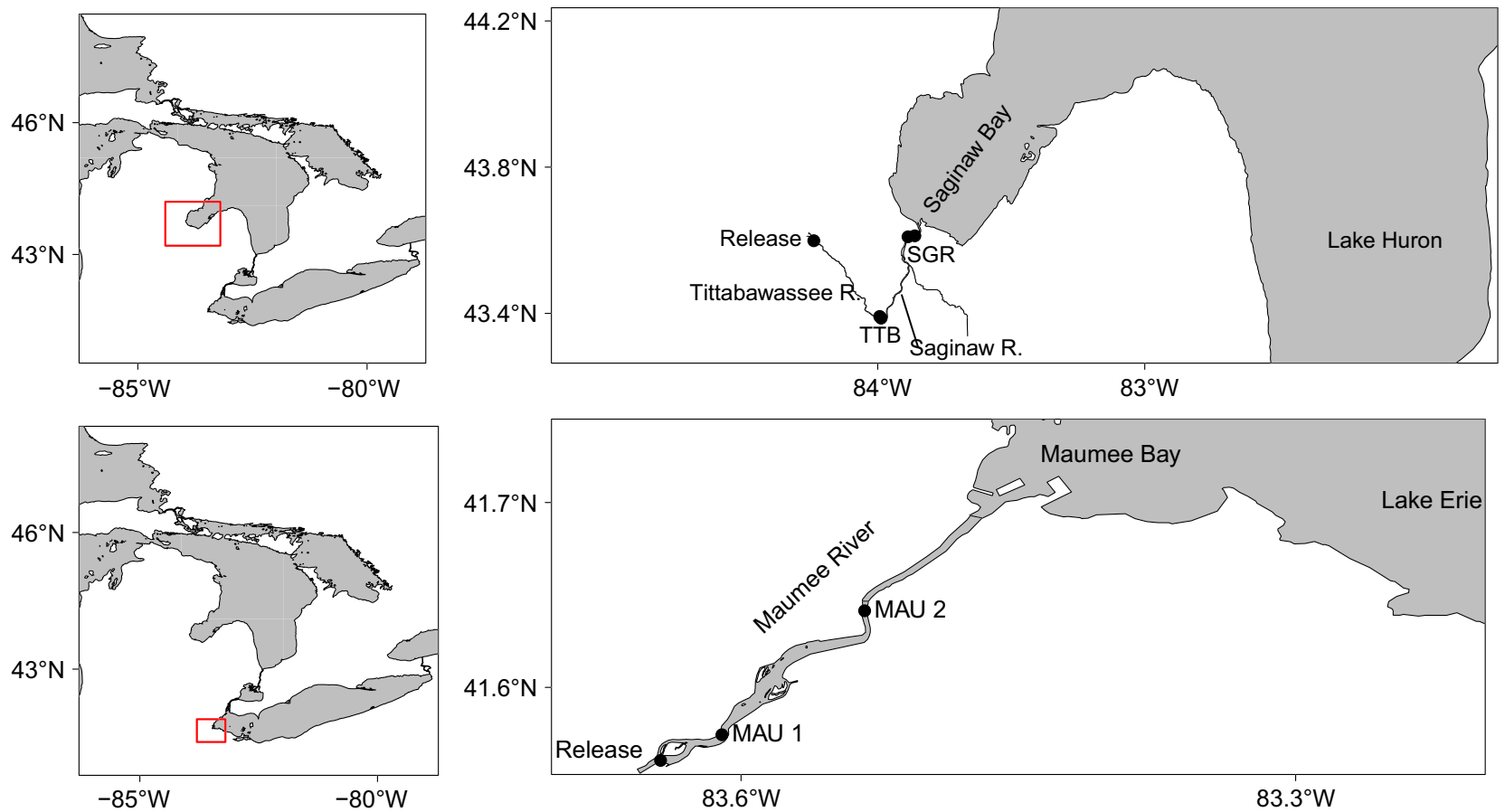

Fig. 1. Map of Saginaw Bay, Tittabawassee River and Saginaw River (top) and Maumee River (bottom). Acoustic receiver lines (black circles) were located near the mouth of the Tittabawassee and Saginaw rivers (top) and at two locations downstream of known spawning grounds in the Maumee River (bottom). Walleye were captured, tagged and released at known spawning ground upstream of the Tittabawassee River receiver lines (labelled 'release') during the 2011 and 2012 spawning season and upstream of the acoustic receivers in the Maumee River. Inset identifies Saginaw Bay region in Lake Huron (top) and Maumee River in Lake Erie (bottom). MAU-2 receiver line was not deployed in 2011. 
movement for each walleye was included in all analyses (Table 3).

General linear models were used to explore the relationship between tagging effects, biological characteristics and rate of postspawn egress of walleye tagged in the Tittabawassee and Maumee rivers. The 2012 and 2013 Tittabawassee River spawning seasons were analysed using separate linear models that included egress as the response variable, sex and tag cohort (2011 or 2012) as categorical predictor variables and fish length at tagging as a continuous predictor variable. Egress of walleye tagged in the Maumee River during the 2012 spawning season was analysed as a function of tag cohort (2011 or 2012) and fish length at tagging. Analysis of egress in the Maumee River was limited to female walleye during the 2012 spawning season as only one male walleye was tagged in the Maumee River in 2012. Only six walleye tagged in 2012 were detected in the Maumee River in 2013 (Table 2). Backwards model selection from a full model containing all variables of interest was used to identify the set of best explanatory variables for each linear model (Data S1). The explanatory power of each predictor variable was assessed by sequentially removing each variable and calculating AIC (Akaike Information Criteria) values (Zuur et al. 2007). If the removal of a predictor variable from the model resulted in decreased AIC values, the predictor variable was not included in the final model. Residual plots were used to validate model fit and assumptions. Length of walleye was centred and duration of egress was log-transformed for analysis. All linear models were fit using the 'Im' function in R software (version 3.1.3).

\section{Results}

A total of 492 walleye were tagged with acoustic transmitters in the Tittabawassee and Maumee rivers in 2011 and 2012 (Tables 1 and 2). Of the total fish tagged, $80 \%$ of the fish were tagged in 2011, with nearly equal numbers of male $(N=100)$ and female $(N=100)$ walleye in both rivers (Tables 1 and 2). In 2012, nearly equal number of males $(N=29)$ and females $(N=30)$ were tagged from the Tittabawassee

Table 3. Duration of time (h) between initial release (following intracoelomic tagging procedure) and first detection of fish passage on the Tittabawassee River (TR) receiver line and the upstream Maumee River (MR) receiver line.

\begin{tabular}{llccrr}
\hline Location & Release & Mean & Min & Max & \multicolumn{1}{c}{ SD } \\
\hline TR & 2011 & 370.1 & 25 & 865.9 & 222.2 \\
TR & 2012 & 547 & 14.9 & 1086.6 & 285.4 \\
MR & 2012 & 29.3 & 0.7 & 229.5 & 48.2 \\
\hline
\end{tabular}

River, but of the 33 fish tagged in the Maumee River, only one individual was male (Tables 1 and 2).

During the 2011 spawning season, $95 \%$ of walleye tagged in the Tittabawassee River moved downstream and were detected at the mouth of the Saginaw River (Table 1). In total, 53\% of walleye tagged in 2011 returned to the Tittabawassee River during the 2012 spawning season and were detected later moving downstream in 2012. A total of 64 walleye (34\%) originally tagged in 2011 were detected moving downstream in 2013. Similarly, 96\% of walleye tagged in 2012 were detected moving downstream during the 2012 spawning season and a further $61 \%$ were detected in the 2013 spawning season. Mean length of walleye detected moving downstream in the Tittabawassee River was $576 \mathrm{~mm}(\mathrm{SE}=5.5 \mathrm{~mm})$ for female walleye and $512 \mathrm{~mm}(\mathrm{SE}=3.8 \mathrm{~mm})$ for male walleye. Walleye tagged in the Tittabawassee River did not return upstream to the Tittabawassee River after they were detected downstream on the Saginaw River receiver line within a spawning season. The optimal general linear model for walleye egress in the Tittabawassee River for the 2012 spawning event only included a predictor variable for release cohort (2012 or 2013) year. All other predictor variables (fish length, sex) did not increase explanatory power of the model and were not retained in the optimal model. For the 2013 walleye spawning event in the Tittabawassee, only sex as a variable improved the explanatory power of the model and subsequently was retained in the optimal model. In addition to sex, release cohort was included in optimal model for the 2013 spawning event to address the objective of this study.

On average, downstream movement (egress) time in the Tittabawassee River calculated from backtransformed linear model estimates was $11 \mathrm{~h}$ greater during the 2012 spawning season for individuals tagged in 2012 compared to individuals tagged in 2011. Back-transformed $95 \%$ confidence intervals for time of mean egress estimated from the linear model ranged from 26.0 to $31.9 \mathrm{~h}$ for walleye released in 2011 and 33.4 to $43.5 \mathrm{~h}$ for walleye released in 2012 (Fig. 2). We did not detect a response on egress time for any other predictor variables included in model selection (i.e. release cohort, fish length, sex). The difference between mean egress time (i.e. effect size) estimated from linear model for fish tagged and released in 2011 and 2012 during the 2012 spawning event was approximately $1.3 \mathrm{~h}$ (back-transformed 95\% CI: 1.1-1.6 h). No differences in mean egress time were detected for walleye tagged in 2011 and 2012 that returned to the Tittabawassee River during the 2013 spawning event (Fig. 2). The optimal model identified by model selection included fish sex (Fig. 2), suggesting that mean egress of male walleye 
Do implanted sensory tags impact the behaviour of fish?

Fig. 2. Mean ( $\pm 95 \%$ confidence intervals) egress time (h) of males and female walleye moving downstream between the Tittabawassee and Saginaw river mouths in spring 2012 (top panel) and spring 2013 (bottom panel) determined with acoustic telemetry. Walleye were captured and tagged near the spawning grounds in spring 2011 and spring 2012 (tagging year).

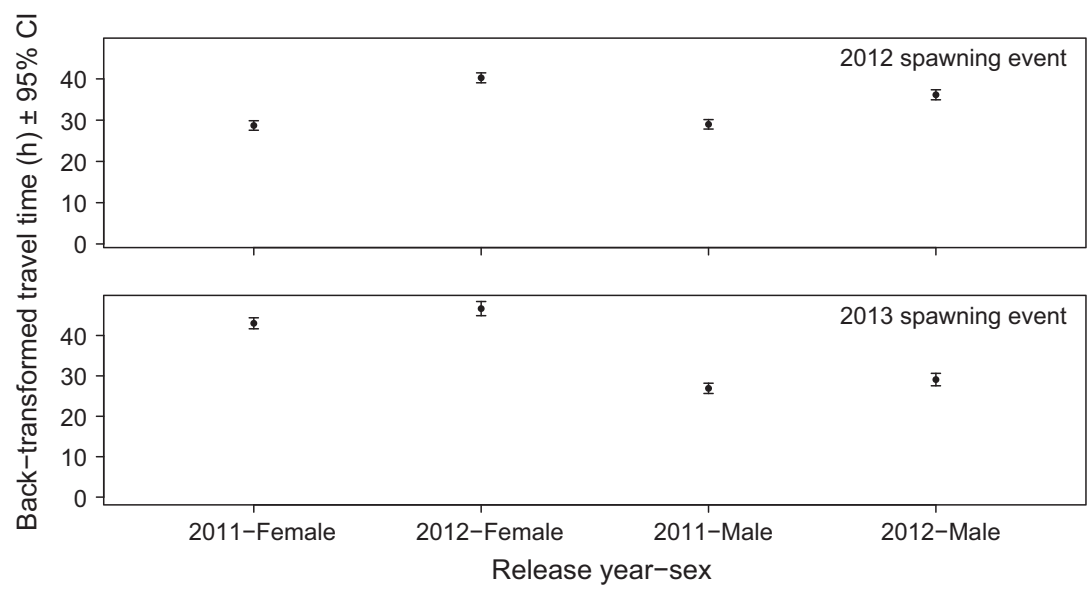

was different than observed for female walleye in 2013 (Fig. 2). Male walleye tagged in 2011 or 2012 had shorter egress times compared to female walleye tagged in the same years during the 2013 spawning event. Linear model predicted that effect size (i.e. difference between mean egress time) for tag cohort (2011 and 2012) in the Tittabawassee River during the 2013 spawning event was approximately $1.1 \mathrm{~h}$ (back-transformed 95\% CI: 0.7-1.6 h). Analysis of model residuals identified two statistical outliers in walleye egress time during spring 2012 in the Tittabawassee River. Egress time for those individuals was approximately 3 and 11 times greater than travel time of the next largest individual and approximately 9 and 33 times greater than the mean egress time estimated for walleye movements between the Tittabawassee and Saginaw river mouths. Further inspection of the detection histories $(>1000$ detections for each fish) of these two walleye revealed that these individuals resided within detection range $(\sim 1 \mathrm{~km})$ of Saginaw and Tittabawassee receiver lines for extended periods of time during the spring and summer of 2012, apparently having taken up river residence and not moving out into Saginaw Bay. Due to extended river residence, those two individuals were excluded from the analysis.

Walleye tagged in the Maumee River moved downstream and were detected on two receiver lines in 2012 and 2013 (Tables 1 and 2). The number of walleye tagged in 2011 that were observed moving downstream in the Maumee River was relatively similar during the 2012 and 2013 spawning seasons (Table 2). Mean length of male walleye detected in the Maumee River was $545 \mathrm{~mm}(\mathrm{SE}=16.2)$ and $627 \mathrm{~mm}(\mathrm{SE}=6.5)$ for female walleye.

The optimal model to explore egress of walleye in the Maumee River during the 2012 spawning event included only the release cohort. Insufficient evidence was available to conclude that egress time was influenced by fish length in the linear model of postspawning Maumee River egress during the 2012 spawning event.

In the Maumee River during the 2012 spawning season, mean egress time of female walleye tagged in 2012 was longer than individuals previously tagged in 2011. Fish length did not influence downstream movement rates in the Maumee River. Estimates of egress time from linear model suggested that walleye tagged and released in 2012 took 10 hours longer to egress between receiver lines than walleye tagged and released in 2011 (back-transformed 95\% confidence intervals, 2011 release: 10.7-16.6 h, 2012 release: 20.8-34.3 h). Nine walleye (seven female and two male) in the Maumee River were detected on the upstream receiver line after detection on the downstream receiver line and completed multiple downstream movements within a spawning season.

\section{Discussion}

Our results support the notion that procedures used for the implantation of intracoelomic tags (i.e. collection, electroanaesthesia and surgery) can impact fish behaviour in the short term. However, it is unclear whether the tagging effect reported here is large enough to be considered ecologically relevant. We observed longer egress times (10-20 h difference) during the spawning period by fish tagged in a given year than those fish tagged in a previous year. Differences in egress time did not appear to be related to fish length, suggesting that the observed variation is likely due to the tagging procedure. Similar post-tagging effects were observed between the sexes. The effects of tagging were apparently ameliorated over time as in 2013 we did not observe differences in egress time between fish tagged in 2011 and 2012. Although amelioration of tagging effects over time may explain the lack of a tagging effect during the 2013 spawning event in the Tittabawassee River, another plausible explanation is decreased statistical 
power resulting from smaller numbers of observed fish in 2013 which may have prevented the detection of a tagging effect of the same magnitude as that observed in 2012. The range of the $95 \%$ confidence intervals estimated for mean differences in egress between walleye tagged in 2011 and 2012 during the 2012 and 2013 spawning events was different, indicating a statistical power to reject the null hypothesis tested by the linear models (Colegrave \& Ruxton 2003).

While we can only limit our conclusions to the two groups of fish used in the current study (without an ideal 'untagged' control group for the study), this study nonetheless is still among the few to examine the potential behavioural consequences of intracoelomic implantation and the presence of the transmitter on fish in the wild. Two exceptions were recent studies of adult lake sturgeon (Acipenser fulvescens) by Hondorp et al. (2015) and adult Atlantic sturgeon (Acipenser medirostris) by Balazik (2015). Similar to our study, these investigations compared current year tagged sturgeon to sturgeon tagged in previous years. In both cases, no effects of the tagging procedures were detected.

Evidence regarding the potential consequences of fish tagging/surgery has largely been mixed among field and laboratory studies, with examples on wild fishes being comparatively scarce. For example, Cooke \& Bunt (2001) compared the effects of internally coiled radiotransmitters and those where the antenna exited the body on swimming activity in smallmouth bass (Micropterus dolomieu) and found no observable differences between test groups. Jepsen \& Aarestrup (1999) compared radio-tagged and dye-marked adult pike (Esox lucius) in a reservoir and did not find any significant differences in morphometrics (weight, length, condition) after one year. Similarly, Jepsen et al. (2008) compared the effects of surgical implants with and without external antennae in brown trout (Salmo trutta) in the wild and found minor differences between control and antennae treatments, with tagging adversely affecting growth. In the laboratory, Thoreau \& Baras (1997) used motion-sensitive transmitters to track tilapia (Oreochromis aureus) recovering from anaesthesia and surgical procedures; they also found no difference in the normal diurnal activity rhythm between focal and control fish (although there was a reduction in overall activity for $12-24 \mathrm{~h}$ postsurgery). Importantly, the size of the tag being used is also likely a factor in determining the effects of tags on fish behaviour. Jadot et al. (2005) compared the effects of tags representing 2 and $6 \%$ of the mass of salema (Sarpa salpa) on activity and group dynamics, finding significant impacts of the large tags on behaviour.
Altered behaviour could lead to premature fallback in rivers and make it difficult to reach ideal feeding grounds and secure the resources needed for growth and gonadal development. Unfortunately, we did not recapture fish in sufficient numbers to assess growth or reproductive investment (e.g. GSI). While rarely considered in tagging effects studies (Cooke et al. 2011), the possibility of potential impacts on reproductive traits such as gonadal development (Baras et al. 2000), egg retention (Berejkian et al. 2007) or the onset of secondary sexual characteristics (Close et al. 2003) has been described on a number of occasions. Even the slight difference between individuals sampled across years in our study suggests that a measurable impact occurred and as such, caution should be taken when tagging fish close to their respective spawning periods. Additional studies are needed to properly explore the potential implications of these practices during critical reproductive periods.

The effects we observed may have been the consequence of (i) the process of collecting the fish (i.e. via electrofishing), (ii) the surgical procedure (including electroanaesthesia and laparotomy), (iii) the presence of the tag or (iv) a combination of these factors. If the presence of the tag has been a major contributing factor, we would have expected to observe size-specific trends reflecting a greater tag burden in smaller individuals; however, this was not the case. Likely the tagging procedure itself (including handling and collection) caused the underlying observed differences. In addition, fish (of all sizes) likely require some time to compensate [in terms of buoyancy (Fried et al. 1976; Perry et al. 2001) and swimming ability (Thorstad et al. 2000; Brown et al. 2006)] for the added burden of the transmitter. The effect of this burden should be reduced/absent after one year. Although we did not measure fish mass directly, using relevant length-weight relationships, the smallest fish we tagged $(\sim 450 \mathrm{~mm})$ would have weighed $\sim 900 \mathrm{~g}$, which would yield a tag burden of $1.3 \%$ (using mass of tag in water) with the largest individuals exceeding $4 \mathrm{~kg}$ yielding burdens of $\sim 0.3 \%$. Hence, the ratios of tag to body mass in our study were relatively low (less than the so-called $2 \%$ rule; Winter 1983), and some species of fish have recently been reported to have been implanted with tag burdens larger than $2 \%$ without ill effect (Brown et al. 1999; Jepsen et al. 2004).

Our study provides a multiyear exploration of the potential impacts of internal electronic tags and associated collection and surgical procedures of fish egress time in a spawning area. While the importance of our findings for walleye spawning ecology and management is unknown, our results do suggest that the capture and tagging procedure and/or the presence of the tag slowed downstream movement 
immediately after implanting transmitters. Because travel time decreased between years, researchers should consider the potential value of censoring data or at least understanding its potential biases in the days following surgical implantation. Researchers should assume that the process of capturing and implanting intracoelomic transmitters likely alters fish behaviour to some extent, and when feasible, postrelease behaviour should be evaluated as a component of future telemetry studies.

\section{Ethics statement}

The project was reviewed and approved by the Carleton University Animal Care Committee in accordance with the Canadian Council of Animal Care Guidelines for the Use of Fish in Research (Project number 8890; Approval number B10-29).

\section{Acknowledgements}

We thank Ohio Department of Natural Resources and Michigan Department of Natural Resources for facilitating walleye collection, and the US Geological Survey for logistical and technical support. We thank Karen Murchie, Sean Landsman, Sarah Seegert and Scott Miehls for assistance with fish surgery. This work was funded by the Great Lakes Fishery Commission by way of Great Lakes Restoration Initiative appropriations (GL-00E23010-3). This paper is contribution 19 of the Great Lakes Acoustic Telemetry Observation System (GLATOS). Cooke is further supported by the Canada Research Chairs Program and the Natural Sciences and Engineering Research Council of Canada. Mention of trade names or commercial products does not imply endorsement by the U. S. Government. This article is contribution 2002 of the U.S. Geological Survey, Great Lakes Science Center.

\section{References}

Balazik, M.T. 2015. Capture and brief invasive procedures using electronarcosis does not appear to affect post-release habits in male Atlantic sturgeon during the spawning season. North American Journal of Fisheries Management 35: 398402.

Baras, E., Malbrouck, C., Houbart, M., Kestemont, P. \& Melard, C. 2000. The effect of PIT tags on growth and physiology of age-0 cultured Eurasian perch Perca fluviatilis of variable size. Aquaculture 185: 159-173.

Berejkian, B.A., Brown, R.S., Tatara, C.P. \& Cooke, S.J. 2007. Effects of telemetry transmitter placement on egg retention in naturally spawning, captively reared steelhead. North American Journal of Fisheries Management 27: 659-664.

Bridger, C.J. \& Booth, R.K. 2003. The effects of biotelemetry transmitter presence and attachment procedures on fish physiology and behavior. Reviews in Fisheries Science 11: 13-34.

Brown, R.S., Cooke, S.J., Anderson, W.G. \& McKinley, R.S. 1999. Evidence to challenge the " $2 \%$ rule" for biotelemetry.
North American Journal of Fisheries Management 19: 867871.

Brown, R.S., Geist, D.R., Deters, K.A. \& Grassell, A. 2006. Effects of surgically implanted acoustic transmitters $>2 \%$ of body mass on the swimming performance, survival and growth of juvenile sockeye and Chinook salmon. Journal of Fish Biology 69: 1626-1638.

Brown, R.S., Eppard, M.B., Murchie, K.J., Nielsen, J.L. \& Cooke, S.J. 2011. An introduction to the practical and ethical perspectives on the need to advance and standardize the intracoelomic surgical implantation of electronic tags in fish. Reviews in Fish Biology and Fisheries 21: 1-9.

Close, D.A., Fitzpatrick, M.S., Lorion, C.M., Li, H.W. \& Schreck, C.B. 2003. Effects of intraperitoneally implanted radio transmitters on the swimming performance and physiology of Pacific lamprey. North American Journal of Fisheries Management 23: 1184-1192.

Colegrave, N. \& Ruxton, G.D. 2003. Confidence intervals are a more useful complement to nonsignificant tests than are power calculations. Behavioral Ecology 14: 446-450.

Cooke, S.J. \& Bunt, C.M. 2001. Assessment of internal and external antenna configurations of radio transmitters implanted in smallmouth bass. North American Journal of Fisheries Management 21: 236-241.

Cooke, S.J., Hinch, S.G., Wikelski, M., Andrews, R.D., Kuchel, L.J., Wolcott, T.G. \& Butler, P.J. 2004. Biotelemetry: a mechanistic approach to ecology. Trends in Ecology \& Evolution 19: 334-343.

Cooke, S.J., Woodley, C.M., Eppard, M.B., Brown, R.S. \& Nielsen, J.L. 2011. Advancing the surgical implantation of electronic tags in fish: a gap analysis and research agenda based on a review of trends in intracoelomic tagging effects studies. Reviews in Fish Biology and Fisheries 21: 127-151.

Cooke, S.J., Hinch, S.G., Lucas, M.C. \& Lutcavage, M. 2012. Biotelemetry and biologging. In: Zale, A.V., Parrish, D.L., Sutton, T.M., eds. Fisheries techniques. Bethesda, MD: American Fisheries Society, pp. 819-860.

Cooke, S., Midwood, J., Thiem, J., Klimley, P., Lucas, M., Thorstad, E., Eiler, J., Holbrook, C. \& Ebner, B. 2013. Tracking animals in freshwater with electronic tags: past, present and future. Animal Biotelemetry 1: 5.

Crowe, W.R. 1962. Homing behavior in walleyes. Transactions of the American Fisheries Society 91: 350-354.

Dick, T.A., Gallagher, C.P. \& Yang, A. 2009. Summer habitat use of Arctic char (Salvelinus alpinus) in a small Arctic lake, monitored by acoustic telemetry. Ecology of Freshwater Fish 18: 117-125.

Fried, S.M., McCleave, J.D. \& Stred, K.A. 1976. Buoyancy compensation by Atlantic salmon (Salmo salar) smolts tagged internally with dummy telemetry transmitters. Journal of the Fisheries Research Board of Canada 33: 1377-1380.

Hahn, L., Agostinho, A.A., English, K.K., Carosfeld, J., da Camara, L.F. \& Cooke, S.J. 2011. Use of radiotelemetry to track threatened dorados Salminus brasiliensis in the upper Uruguay river, Brazil. Endangered Species Research 15: $103-114$.

Hayden, T.A., Holbrook, C.M., Fielder, D., Vandergoot, C.S., Bergstedt, R.A., Dettmers, J.M., Krueger, C.C. \& Cooke, S.J. 2014. Acoustic telemetry reveals large-scale migration patterns for walleye in Lake Huron. PLoS One 9: e114833. 


\section{Wilson et al.}

Hightower, J.E., Jackson, J.R. \& Pollock, K.H. 2001. Use of telemetry methods to estimate natural and fishing mortality of striped bass in Lake Gaston, North Carolina. Transactions of the American Fisheries Society 130: 557-567.

Hockersmith, E.E., Muir, W.D., Smith, S.G., Sandford, B.P., Perry, R.W., Adams, N.S. \& Rondorf, D.W. 2003. Comparison of migration rate and survival between radio-tagged and PIT-tagged migrant yearling chinook salmon in the snake and Columbia rivers. North American Journal of Fisheries Management 23: 404-413.

Hondorp, D.W., Holbrook, C.M. \& Krueger, C.C. 2015. Effects of acoustic tag implantation on lake sturgeon Acipenser fulvescens: lack of evidence for changes in behavior. Animal Biotelemetry 3: 44. DOI 10.1186/s40317-015-0085-0

Jadot, C., Donnay, A., Ylieff, M. \& Poncin, P. 2005. Impact implantation of a transmitter on Sarpa salpa behaviour: study with a computerized video tracking system. Journal of Fish Biology 67: 589-595.

Jepsen, N. \& Aarestrup, K. 1999. A comparison of the growth of radio-tagged and dye-marked pike. Journal of Fish Biology 55: 880-883.

Jepsen, N., Koed, A., Thorstad, E.B. \& Baras, E. 2002. Surgical implantation of telemetry transmitters in fish: how much have we learned? Hydrobiologia 483: 239-248.

Jepsen, N., Schreck, C.B., Clements, S. \& Thorstad, E.B. 2004. A brief discussion on the $2 \%$ tag/bodymass rule of thumb. In: Spedicato, M.T., Lembo, G., Marmulla, G., eds. Aquatic telemetry: advances and applications: proceedings of the fifth conference on fish telemetry held in Europe. Rome: FAO/COISPA, pp. 255-259.

Jepsen, N., Mikkelsen, J.S. \& Koed, A. 2008. Effects of tag and suture type on survival and growth of brown trout with surgically implanted telemetry tags in the wild. Journal of Fish Biology 72: 594-602.

Khan, M.T., Khan, T.A. \& Wilson, M.E. 2004. Habitat use and movement of river blackfish (Gadopsis marmoratus R.) in a highly modified Victorian stream, Australia. Ecology of Freshwater Fish 13: 285-293.

Liedtke, T.L. \& Rub, A.M.W. 2012. Techniques for telemetry transmitter attachment and evaluation of transmitter effects on fish performance. In: Adams, N.S.,Beeman, J.W., Michelle, W.R., eds. Telemetry techniques: a user guide for fisheries research. Bethesda, Maryland USA: American Fisheries Society, pp. $45-87$.

Lucas, M.C. \& Baras, E. 2000. Methods for studying spatial behaviour of freshwater fishes in the natural environment. Fish and Fisheries 1: 283-316.

Matter, A.L. \& Sandford, B.P. 2003. A comparison of migration rates of radio- and PIT-tagged adult snake river chinook salmon through the Columbia river hydropower system. North American Journal of Fisheries Management 23: 967-973.

McKenzie, J.R., Parsons, B., Seitz, A.C., Kopf, R.K., Mesa, M.G. \& Phelps, Q. 2012. Advances in Fish Tagging and Marking Technology, Bethesda, Maryland USA: American Fisheries Society Symposium.
Mitamura, H., Mitsunaga, Y., Arai, N., Yamagishi, Y., Khachaphichat, M. \& Viputhanumas, T. 2008. Horizontal and vertical movement of Mekong giant catfish Pangasianodon gigas measured using acoustic telemetry in Mae Peum Reservoir, Thailand. Fisheries Science 74: 787-795.

Nielsen, L.A. 1992. Methods of marking fish and shellfish. Bethesda, MD: American Fisheries Society, Special Publication 23.

Olney, J.E., Latour, R.J., Watkins, B.E. \& Clarke, D.G. 2006. Migratory behavior of American shad in the York River, Virginia, with implications for estimating in-river exploitation from tag recovery data. Transactions of the American Fisheries Society 135(4): 889-896.

Peat, T.B., Hayden, T.A., Gutowsky, L.F.G., Vandergoot, C.S., Fielder, D.G., Madenjian, C.P., Murchie, K.J., Dettmers, J.M., Krueger, C.C. \& Cooke, S.J. 2015. Seasonal thermal ecology of adult walleye (Sander vitreus) in Lake Huron and Lake Erie. Journal of Thermal Biology 53: 98-106.

Perry, R.W., Adams, N.S. \& Rondorf, D.W. 2001. Buoyancy compensation of juvenile chinook salmon implanted with two different size dummy transmitters. Transactions of the American Fisheries Society 130: 46-52.

Thoreau, X. \& Baras, E. 1997. Evaluation of surgery procedures for implanting telemetry transmitters into the body cavity of tilapia Oreochromis aureus. Aquatic Living Resources 10: 207-211.

Thorstad, E.B., Økland, F. \& Finstad, B. 2000. Effects of telemetry transmitters on swimming performance of adult Atlantic salmon. Journal of Fish Biology 57: 531-535.

Thorstad, E.B., Hay, C.J., Næsje, T.F. \& Økland, F. 2001. Movements and habitat utilization of three cichlid species in the Zambezi River, Namibia. Ecology of Freshwater Fish 10: 238-246.

Thorstad, E.B., Rikardsen, A.H., Alp, A. \& Økland, F. 2013. The use of electronic tags in fish research - an overview of fish telemetry methods. Turkish Journal of Fisheries and Aquatic Sciences 13: 881-896.

Vandergoot, C.S., Murchie, K.J., Cooke, S.J., Dettmers, J.M., Bergstedt, R.A. \& Fielder, D.G. 2011. Evaluation of two forms of electroanesthesia and carbon dioxide for short-term anesthesia in walleye. North American Journal of Fisheries Management 31: 914-922.

Winter, J.D. 1983. Underwater biotelemetry. Fisheries techniques, Bethesda, Maryland: American Fisheries Society, pp.371-396.

Zuur, A.F., Leno, E.N. \& Smith, G.M. 2007. Analysing ecological data. New York: Springer-Verlag.

\section{Supporting Information}

Additional Supporting Information may be found in the online version of this article:

Data S1.Statistical information regarding analyses for each study site. 